\title{
How does the ectoparasitoid wasp Euplectrus separatae (Hymenoptera: Eulophidae) recognize a suitable oviposition site on the host larva Pseudaletia separata (Lepidoptera: Noctuidae)?
}

\author{
Yutaka NAKAMATSU* and Toshiharu TANAKA \\ Laboratory of Applied Entomology, Graduate School of Bio-Agricultural Sciences, Nagoya University; Nagoya 464-8601, Japan
}

(Received 28 June 2004; Accepted 19 November 2004)

\begin{abstract}
The larval ectoparasitoid of Pseudaletia separata, Euplectrus separatae oviposits exclusively on the dorsolateral surface from the 3rd thoracic to the 2nd abdominal segment of the host. Larval parasitoids are well known to be exposed to risks from aggressive defense behavior when they attempt to parasitize a host. E. separatae female sting the host to inject a venom prior to oviposition. At this time the female wasp is exposed to a serious risk from aggressive host behavior. However, the female avoids the risk by moving to a specific segment of the host. The question arose as to how the female wasp recognizes the specific segments of the host. The female wasp mounted the host larva from the posterior dorsal part and moved forward on the host. The female used chemical cues to recognize the posterior part of the host body. Diethyl ether extracts from the last abdominal segments of the host were more attractive to females than extracts from the head. Motionless behavior in the host after the female wasp mounted did not induce the forward movement of the female wasp. Once the female was on the host she used crawling of the host body (peristaltic movement) as a stimulus to move forward on the host. Another key stimulus to cause the parasitoid to cease movement forward on the specific segments of the host was examined. When a host head was attached to the 3rd abdominal segment, the female wasp shifted the oviposition site adequately behind the head on the host body, suggesting that the head is used as a visual cue to pinpoint a suitable oviposition site.
\end{abstract}

Key words: Stinging behavior; oviposition sites; ectoparasitoid; Pseudaletia separata; Eulophidae

\section{INTRODUCTION}

Euplectrus separatae Kamijo (Hymenoptera: Eulophidae) is a gregarious ectoparasitoid that uses the common armyworm Pseudaletia separata Walker (Lepidoptera: Noctuidae) as a host (Nakamatsu and Tanaka, 2003a). Many ectoparasitoids are known to paralyze permanently or kill the hosts at the time of parasitization (Beard, 1963, 1978; Shaw, 1981; Piek and Spanjer, 1986). However, some ectoparasitic Eulophidae, including E. separatae, allow the hosts to continue feeding after parasitization, although they seem to paralyze their host temporarily (Neser, 1973; Gerling and Limon, 1976; Uematsu, 1986). These parasitoids that use larvae as hosts are at a particular risk during parasitization, because the host larvae can react to parasitization attempts by violent wriggling, biting and spitting as host defense behaviors (Godfray, 1994;
Mattiacci and Dicke, 1995; Potting et al., 1999). Ectoparasitoids that need a long time to parasitize are especially exposed to such risks. E. separatae needs a long time to fix their eggs with pile-like structures to the host integument so the eggs do not fall from the host body during growth (Gerling and Limon, 1976; Nakamatsu and Tanaka, 2003b). Further the offspring of larval ectoparasitoids must avoid host defensive behavior after oviposition because they can be removed through grooming by the host (Vinson and Iwantsch, 1980; Godfray, 1994). The recognition of an oviposition site that avoids these defensive behaviors of the host is therefore an important step for ectoparasitoids to successfully parasitize hosts. Ectoparasitoids can reduce risks for their offspring by ovipositing on specific segments of the host where the host larvae cannot reach them (Baltensweiler and Moreau, 1957). Euplectrus melanocephalus prefers to

* To whom correspondence should be addressed at: E-mail: nakamatu@nuagr1.agr.nagoya-u.ac.jp DOI: $10.1303 /$ aez.2005.185 
oviposit dorsolaterally on one of the first five abdominal segments of the second and third instars of a fruit-piercing moth (Jones and Sands, 1999). Although the relation between the host defense behavior and the oviposition of the parasitoid on the specific sites of the host body have already been reported (Godfray, 1994), it is not clear which cues ectoparasitoids use to determine the oviposition sites to avoid the host defense behaviors. Uematsu (1986) reported that Euplectrus kuwanae paralyzed its host temporally by pre-ovipositional stinging. Temporary paralysis is required for the female wasp to avoid attack from the non-parasitized host at the time of oviposition.

In this study, we confirmed the oviposition sites of E. separatae and discuss the reasons female wasps lay eggs on the specific segments and how they recognize the specific segments.

\section{MATERIALS AND METHODS}

Rearing of insects and parasitization. Pseudaletia separata (Walker) hosts were reared on artificial diet (SilkMate ${ }^{\mathbb{R}}$, Nihon Nohsan Co. Ltd., Kanagawa) under a long day photoregime (16 h light: $8 \mathrm{~h}$ dark) at $25 \pm 1{ }^{\circ} \mathrm{C}$ according to Nakamatsu and Tanaka (2003a). Euplectrus separatae, larval ectoparasitoid wasps were reared with a $30 \%$ sugar solution absorbed on cotton pads in a small plastic tube $(2 \mathrm{~cm}$ in diameter $\times 9.5 \mathrm{~cm}$ in length).

Parasitization was performed by female wasps $6 \mathrm{~d}$ after emergence to induce sufficient ovipositional activity. Twenty host larvae in the 5th stadium and 20 female wasps were placed in a $430 \mathrm{ml}$ plastic cup for $2 \mathrm{~h}$. The parasitized hosts were reared in a $430 \mathrm{ml}$ cup on the artificial diet. The day on which each host larva ecdysed to the next stadium was designated as day 0 .

Pre-ovipositional stinging site and oviposition site. We directly observed which segment of the host the female wasp stung to inject the venom and lay eggs. Twenty 5 th instar host larvae at day 0 and 20 female wasps were used.

Host defense behavior to the parasitoid wasp while pre-ovipositional stinging. The host defensive behavior especially observed at the pre-ovipositional stinging by the parasitoid female led us to carry out the following experiments. Female wasp stinging could be mimicked by pricking the host with an insect pin. A small piece of paper $(0.3 \mathrm{~cm}$ on every side) was set at the middle of the insect pin. The dorsolateral edges of the 3rd thoracic or the 8th abdominal segments of the host body were carefully pricked with the insect pin and the piece of paper slide onto the surface of host integument. Ten replications were performed in each case.

Chemical cues on the posterior part of the host body. It was observed that female wasps walked around the host and then mounted the posterior part of the host body in most cases. The question arose as to how the female wasps recognized the posterior part of the host body. Choice tests were performed to clarify whether the female wasps recognized the anterior and posterior parts of the host. Each of three heads and 9-10th abdominal segments (telson) of nonparasitized host larvae were cut off with scalpel while anesthetized with $\mathrm{CO}_{2}$ gas and extracted for $40 \mathrm{~min}$ in $20 \mathrm{ml}$ of diethyl ether. Extracts were centrifuged at 2,000 rpm for $10 \mathrm{~min}$, placed on one side of a filter-paper strip $(0.5 \times 2.0 \mathrm{~cm}$ in length $)$ and dried. Each strip was placed in a square dish $(14 \times 10 \mathrm{~cm})$ at regular intervals and female wasps released between each strip. Female behavior was observed for $1 \mathrm{~h}$ after release. The female wasp searching time and the number of the wasps that performed the searching behavior on the paper strips was recorded.

Wasp movement from posterior part to oviposition site on the host body. Fifth instar host larvae at day 0 and female wasps were used to observe the female wasp movement to the pre-ovipositional stinging site after mounting on the surface of the host integument.

Key stimulus responsible for the female forward movement and stopping on the specific segments. Forward movement of the female wasp was observed only when the host was moving forward. To clarify the key stimulus for forward movement of the female wasp, the forward movement of the host was halted by fixing the host body on a filter paper with glue (Cyanoacrylate, ARON $\mathrm{ALPHA}^{\circledR}$, Toagosei Co.) in a square petri dish $(14 \mathrm{~cm} \times 10 \mathrm{~cm})$. Five fixed hosts and five female wasps were placed in a petri dish and the oviposition site on the host recorded after $24 \mathrm{~h}$.

Next we considered that the crawling of the host body (peristaltic movement) was important for wasp oviposition behavior. Two types of 5th stadium hosts were prepared. One was pinned in the 
head, the other in the abdomen. The abdomen-fixed host could make peristaltic movement, but the head-fixed host could not. Five head-fixed 5th stadium host larvae were set in a square petri dish $(14 \mathrm{~cm} \times 10 \mathrm{~cm})$ and five female wasps released in the petri dish. The oviposition site on the host was recorded after $24 \mathrm{~h}$. Similarly, the abdomen-fixed hosts were also examined.

Next, to clarify the key stimulus of wasps for stopping at the specific position on the host, heads of nonparasitized hosts were cut off with a scalpel while anesthetized with $\mathrm{CO}_{2}$ gas and the head attached with glue to the 1st thoracic segment of another 5th stadium host. Female wasps were allowed to oviposited as explained above.

\section{RESULTS}

\section{Pre-ovipositional stinging site and oviposition site}

E. separatae female wasps first mounted the posterior part of the host body, then moved to the dorsolateral surface from the 3rd thoracic to the 2nd abdominal segment of the host where the host was unable to attack before the wasp stinging. The female, then anchored each egg with a stalk on the integument of the host without moving from the pre-ovipositional stinging site.

\section{Host defense behavior to parasitoid during pre- ovipositional stinging}

While the female stung the host larva to inject venom, the host turned its head toward the wasp and tried to bite it (Fig. 1A, B). The wasp continued stinging in spite of the host behavior, which included violent wriggling and rubbing of its dorsal surface site against the floor (Fig. 1A, B).

When a small piece of paper was pinned to the dorsolateral edge of the 8th abdominal segment $(N=10$, Fig. 2A), $100 \%$ of the host larvae aggressively attacked and stained the paper with an oral secretion. On the other hand, the host larvae were unable to attack and stain $90 \%$ of the paper pieces on the 3rd thoracic segment $(N=10$, Fig. 2B). These results show that the host larvae can not attack the female wasp dorsolaterally on the surface of the anterior segment behind the head.

Even though the hosts continued to feed and grow without molting after parasitization (Nakamatsu and Tanaka, 2003a), the parasitoid eggs and larvae on the specific dorsal segments were not removed by grooming.

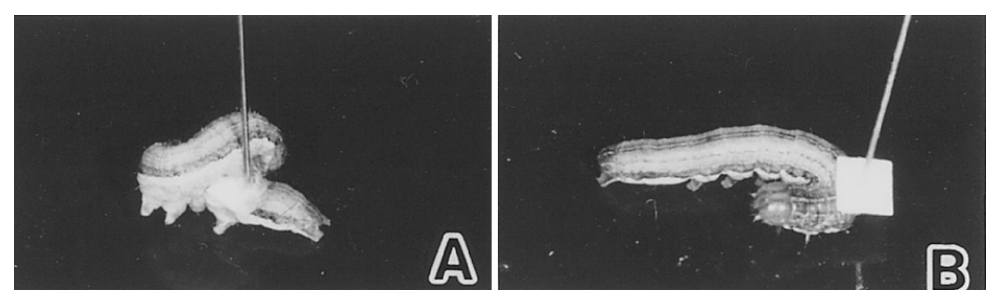

Fig. 1. (A) Host larva bite the small filter paper $(0.3 \mathrm{~cm}$ square) placed on the 8 th abdominal segment. (B) Host larva cannot attack the paper when it is placed on the $3 \mathrm{rd}$ thoracic segment although the host attempts to turn around.
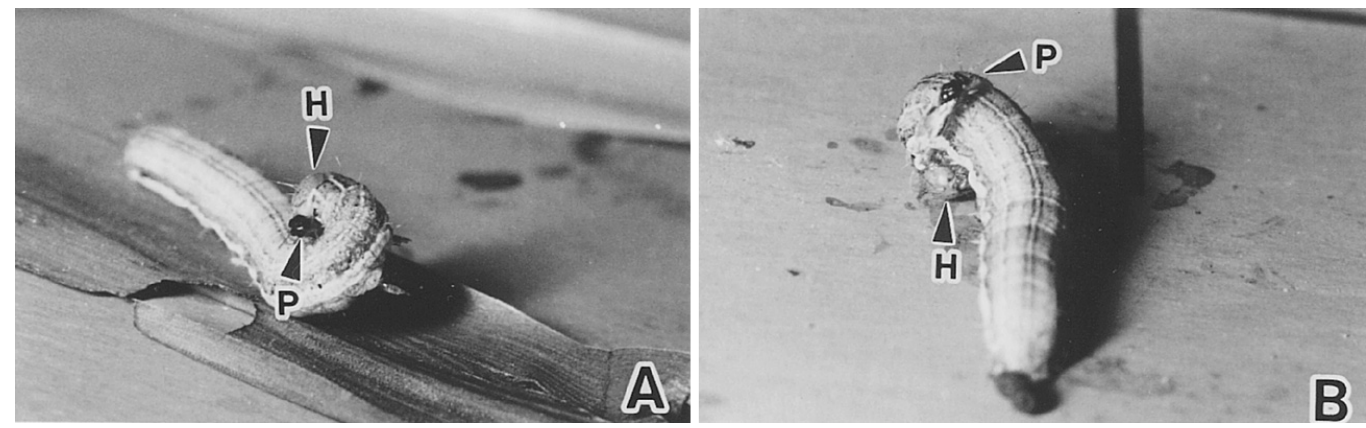

Fig. 2. (A) Biting and spitting behavior of host larva at a parasitoid. (B) Rubbing of dorsal surface of body against the floor by the host. H: head of host larva, P: parasitoid wasp. 
Table 1. Response of the female wasps to diethyl ether extracts from the 10th abdominal segment of 5 th stadium host larvae on day 0

\begin{tabular}{lcccc}
\hline \multicolumn{1}{c}{ Extract } & $\begin{array}{c}\text { Number of } \\
\text { parasitoids walking } \\
\text { on filter paper (1) }\end{array}$ & $\begin{array}{c}\text { Number of } \\
\text { parasitoids showing } \\
\text { searching behavior }(2)\end{array}$ & $\begin{array}{c}\text { Percentage showing } \\
\text { searching behavior* } \\
(2) /(1) \%\end{array}$ & $\begin{array}{c}\text { Duration of } \\
\text { search behaviour } * * \\
(\text { mean } \pm \text { SD) }(\mathrm{s})\end{array}$ \\
\hline Head & 23 & 19 & $82.6 \mathrm{a}$ & $38.9 \pm 36.8 \mathrm{a}$ \\
10th abdominal segment & 25 & 23 & $92.0 \mathrm{a}$ & $97.7 \pm 66.7 \mathrm{~b}$ \\
\hline
\end{tabular}

Means followed by different letters within a column are significantly different (Mann-Whitney $U$-test: * $U=314.5$, ** $U=71$, $p<0.001)$.

\section{Chemical cues of posterior part of the host body}

There is no difference between the percentage of searching behavior for the head and 10th abdominal segment of the host (Table 1). However, the extract from the last abdominal segment caused the females to search longer than with the head extract. Chemicals of the 10th abdominal segment may trigger the wasp searching behavior.

\section{Wasp movement from posterior part to oviposi- tion site on the host body}

The female wasp mounted the posterior part of the dorsal surface of the host body and then moved forward as the host moved forward (Fig. 3). The female remained motionless while the host did not move after having mounted. The forward movement of the host seemed to allow the wasp to recognize the direction of the host head.

Key stimulus responsible for female forward movement and stopping at the specific segments

The oviposition sites were concentrated on the dorsolateral surface of three segments from the $3 \mathrm{rd}$ thoracic to the 2nd abdominal (mean \pm SD: A: Abdominal segment: A1.08 $\pm 0.95, N=26$, Fig. 4A).

When the host was fixed on a filter paper with glue, oviposition occurred near the 5th abdominal segment (Fig. 4B) (mean \pm SD: Control: A1.08 \pm $0.95, N=26$; Fixed: A5.17 $\pm 2.58, N=6$; MannWhitney $U$-test: $U=9, p<0.001)$. Although female wasps mounted the host integument, $65 \%$ could not lay eggs because the host was motionless. Furthermore, when the heads of the hosts were pinned down to halt the forward movement, the hosts moved around the pin abnormally and all female wasps could neither mount nor oviposit on the hosts (Fig. 4C).

However, when the host was pinned on the lat-

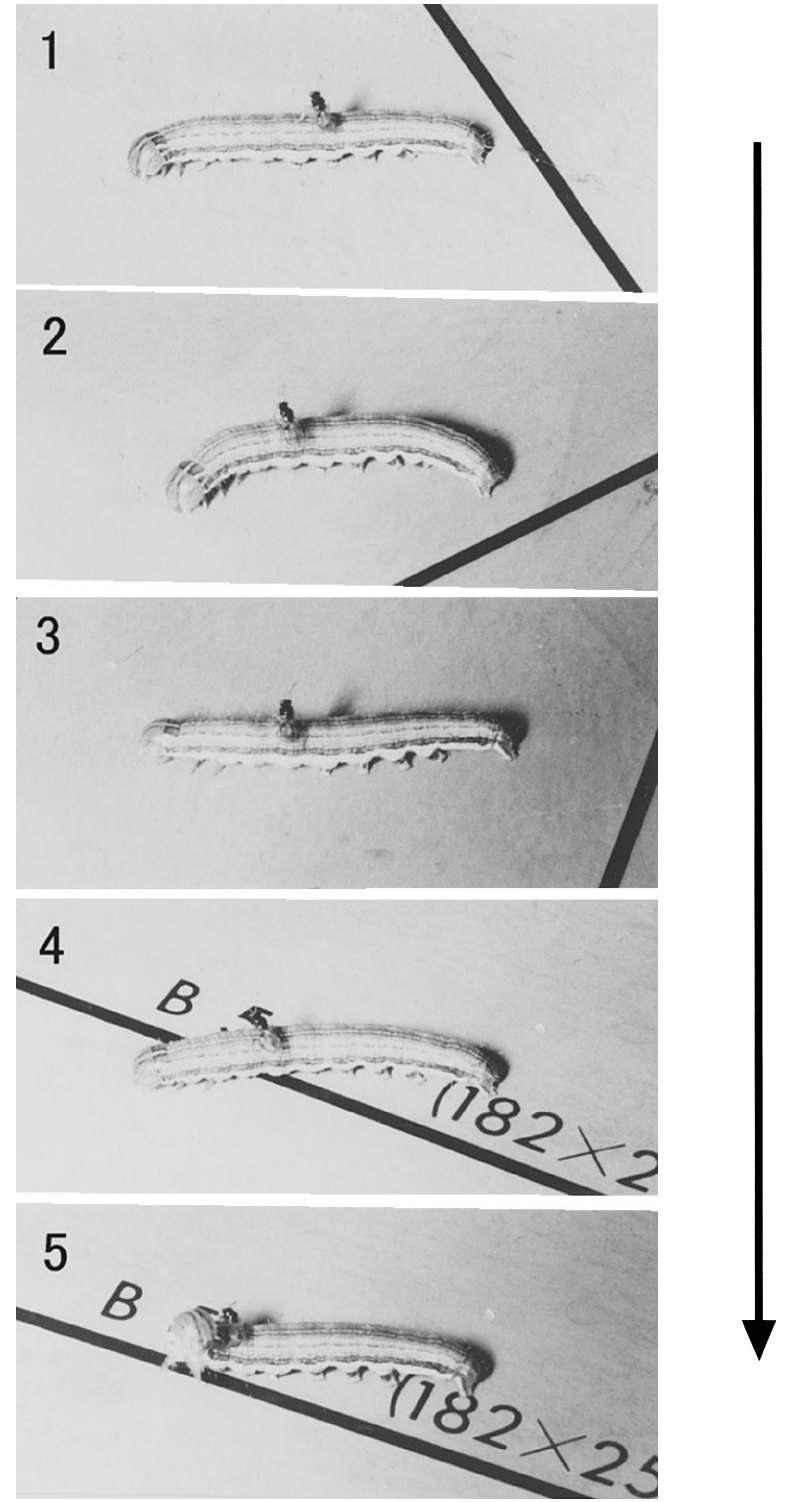

Fig. 3. Forward movement of the female wasp on the host. The last photo shows that the female wasp begins to sting the host with the host turning its head to the wasp as defensive behavior. 


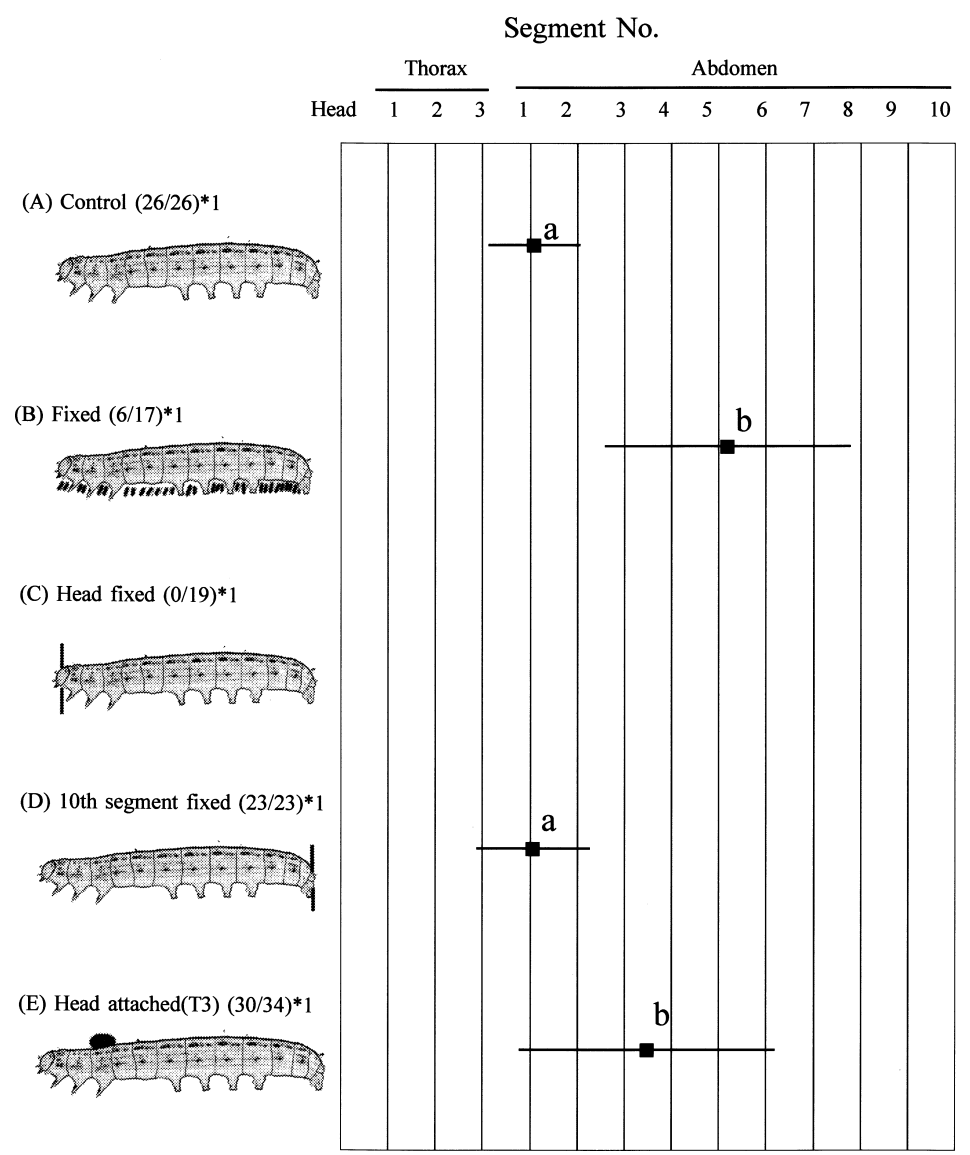

Fig. 4. Oviposition site selected by Euplectrus separatae females with various treatments. (A) Normal oviposition. (B) Hosts were attached on a filter paper with glue. (C) Hosts were anchored on the head with an insect pin. No parasitization occurred because the host moved irregularly. (D) Anchor in the last segment allowed peristaltic movement. (E) The pseudo-head attached on the 1st thoracic segment caused females to mistake the oviposition site. The segments of the host are numbered. The average of oviposition sites and standard deviation are shown in the figure. Different letters on the shoulder of each point indicate significant differences (Mann-Whitney $U$-test, each value is described in the text). ${ }^{* 1}$ (No. of hosts parasitized/No. of host used).

eral edges of the last abdominal segment, the host continued to try moving forward. The peristaltic movements of the host continued even though the host was unable to actually move forward and the wasps oviposited on the 1st abdominal segment of the host as with normal oviposition (Fig. 4D) (mean \pm SD: Control: A1.08 $\pm 0.95, N=26 ; 10$ th segment fixed: A1.06 $\pm 1.18, N=9$; Mann-Whitney $U$-test: $U=146, \mathrm{NS})$. These results suggest that the female wasp recognizes the peristaltic movements of the host after mounting.

The next question addressed was which factors stopped the forward movement of the female wasp at the accurate oviposition site on the host body. The pseudo-head attached to the 3rd thoracic segment caused oviposition on the 4th abdominal segment (Fig. 4E). The pseudo-head attached on the 3rd thoracic segment appeared to reflect the state that the host raised its head. This suggests that female wasps determine the oviposition site by recognizing the head of the host while she moves forward (Fig. 4E) (mean \pm SD: Control: A1.08 \pm 0.95 , $N=26$; Head attached (T3): A3.47 $\pm 2.68, N=30$; Mann-Whitney $U$-test: $U=216, p<0.01)$.

\section{DISCUSSION}

This study leads to the conclusions that female wasps initially recognize the posterior segments with the help of chemicals of the last segment of the host and then mounts the host body. After mounting the host body, the females recognize the front of the host by the crawling of the host body (peristaltic movement) and move forward stopping at the appropriate site to sting with the visual help of the host head. 
Although ectoparasitoids in the Eulophidae family can temporarily paralyze the hosts (Neser, 1973; Gerling and Limon, 1976; Uematsu, 1986), their first stinging behavior before oviposition must be performed on non-paralyzed hosts and these ectoparasitoids must avoid the host defense behavior at the time of stinging. If the ectoparasitoid wasp stings on the posterior part of the host body, the wasp will be attacked with digestive fluids and mandibles as seen with the pieces of paper (Fig. 1). Especially the Euplectrus wasp must spend a long time on the host body to inject venom (Uematsu, 1986). Most Euplectrus wasps oviposit mainly on the thorax and anterior abdominal segments of the host larva (Neser, 1973; Well and Berberet, 1974; Uematsu, 1981; Jones and Sands, 1999). However, E. laphygmae lay eggs on all dorsal segments of young hosts, but the oviposition site is limited to the dorsal segments of older hosts (Chattergee, 1945). Gerling and Limon (1976) reported that this oviposition behavior is correlated with the agility and ability to remove parasitoid eggs by older hosts. We showed that selection of restricted anterior segments of the host by E. separatae as a preovipositional stinging site is likely to allow the female wasps to escape from the host aggressive defense. Therefore, it is advantageous for the female wasp to recognize the appropriate site on the host body at oviposition.

Female ectoparasitoids are exposed to host defense behavior not only at the time of stinging, but also after oviposition, because the eggs can be removed as a result of grooming by the host (Vinson and Iwantsch, 1980; Godfray, 1994). The Pseudaletia host did not attack the Euplectrus larvae on the posterior part. Therefore, we think this dangerous condition for the parasitoid is limited to the behavior at the time of stinging in the Euplectrus separatae-Pseudaletia separata system.

E. laphygmae females examine their host with antennae, and then mount the back (Gerling and Limon, 1976). It was also observed that the E. separatae female preferentially examined the 9-10th abdominal segments with her antennae before mounting the host body. This observation supports the findings that diethyl ether extracts from the 10th abdominal segment attracted females for a longer time than the control (Table 1). The odors from the last abdominal segments may be used to determine the anterior and posterior sites on the host at a short distance.

The absence of forward movement after having mounted the hosts misled the female wasps to oviposit on the specific segments. The host bodies attached to filter paper with glue absolutely halted the forward movement of the host (Fig. 4B), resulting in female wasps stinging near the 5 th abdominal segments. These results suggest that the forward movement of the host is required for females to recognize a suitable site for pre-ovipositional stinging. Because the female wasps correctly oviposited on the abdomen-fixed host larvae, the wasps oviposition behavior needs the crawling (peristaltic movement) of the host, but not the forward movement.

The wasp movement to a specific position depends on the peristaltic movement of the host. However, we didn't clarified factors of the host peristaltic movement that control the behavior of the wasp. The peristaltic movement of the host affecting the wasp behavior needs to be studied in detail.

\section{ACKNOWLEDGEMENTS}

We thank Y. Kitamori, H. Kuwahara and other students at Shugakukan High-School, Yatsushiro City, Kumamoto Prefecture for their assistance with the experiments. We also express our gratitude to Kazuaki Kamijo at the Hokkaido Forest Experiment Station for identification of parasitoid species and to Nishioka and colleagues of Kagoshima Agricultural Experiment Station for their help in collecting Pseudaletia separata larvae.

\section{REFERENCES}

Baltensweiler, V. W. and J. P. Moreau (1957) Ein Beitrag biologisch-systematischer Art zur Kenntnis der Gattung Phytodietus (Hymenoptera). Zeit. Ang. Entomol. 41: 272-276.

Beard, R. L. (1963) Insect toxins and venoms. Ann. Rev. Ent. 8: 1-18.

Beard, R. L. (1978) Venom of Braconidae. In Arthropod Venoms (S. Bettini ed.). Springer-Verlag, Berlin, pp. 773800.

Chattergee, P. N. (1945) On the biology and morphology of Euplectrus parvulus Férr. (Hymenoptera: Eulophidae). Ind. J. Entomol. 6: 95-101.

Gerling, D. and S. Limon (1976) A biological review of the genus Euplectus (Hym.: Eulophidae) with special emphasis on E. laphygmae as a parasite of Spodoptera littoralis (Lep.: Noctuidae). Entomophaga 21: 179-187.

Godfray, H. C. J. (1994) Parasitoids: Behavioral and Evolutionary Ecology. Princeton University Press, Princeton. 473 pp.

Jones, P. and D. Sands (1999) Euplectrus melanocephalus 
Girault (Hymenoptera: Eulophidae), an ectoparasitoid of larvae of fruit-piercing moths (Lepidoptera: Noctuidae: Catocalinae) from northern Queensland. Aust. J. Entomol. 38: 377-381.

Mattiacci, L. and M. Dicke (1995) The parasitoid Cotesia glomerata (Hymenoptera: Braconidae) discriminates between first and fifth larval instars of its host Pieris brassicae, on the basis of contact cues from frass, silk, and herbivore-damaged leaf tissue. J. Insect Behav. 8: 485-498.

Nakamatsu, Y. and T. Tanaka (2003a) Venom of ectoparasitoid, Euplectrus sp. near plathypenae (Hymenoptera: Eulophidae) regulates the physiological state of Pseudaletia separata (Lepidoptera: Noctuidae) host as a food resource. J. Insect Physiol. 49: 149-159.

Nakamatsu, Y. and T. Tanaka (2003b) Development of a gregarious ectoparasitoid, Euplectrus separatae (Hymenoptera: Eulophidae), that parasitizes Pseudaletia separata (Lepidoptera: Noctuidae). Arthr. Struct. Develop. 32: 329-336.

Neser, S. (1973) Biology and behaviour of Euplectrus near laphygmae Ferriere (Hymenoptera: Eulophidae). Ent. Mem. Dep. Agric. Tech. Serv. South Afr. 32: 1-31.

Piek, T. and W. Spanjer (1986) Chemistry and pharmacology of solitary wasps venoms. In Venoms of the Hy- menoptera: Biochemical, Pharmacological and Behavioural Aspects (T. Piek ed.). Academic Press, London, pp. 161-289.

Potting, R. P. J., W. A. Overholt, F. O. Danso and K. Takasu (1999) Foraging behavior and life history of the stemborer parasitoid Cotesia flavipes (Hymenoptera: Braconidae). J. Insect Behav. 10: 13-29.

Shaw, M. R. (1981) Delayed inhibition of host development by the nonparalyzing venoms of parasitic wasps. J. Invert. Pathol. 37: 215-221.

Uematsu, H. (1981) Bionomics of Euplectrus kuwanae Crawford (Hymenoptera: Eulophidae), a parasitoid of Argyrogramma albostriata. Appl. Entomol. Zool. 16: $57-59$.

Uematsu, H. (1986) Preovipositional stinging of an external parasitoid, Euplectrus kuwanae Crawford (Hymenoptera: Eulophidae). Jpn. J. Appl. Entomol. Zool. 30: 55-57 (in Japanese with English summary).

Vinson, S. B. and G. F. Iwantsch (1980) Host regulation by insect parasitoids. Q. Rev. Biol. 55: 143-165.

Well, R. and R. C. Berberet (1974) The life cycle of Euplectrus platyhypenae, a gregarious external parasitoid of peanut foliage feeders in Oklahoma. Environ. Entomol. 3: 744-746. 